\title{
Research on Operation and Management Mode of the Optical Valley International Tennis Center
}

\section{Liu Pei}

Professional of Tennis College, Wuhan City Polytechnic, Wuhan, China

\section{Email address:}

378880308@qq.com

\section{To cite this article:}

Liu Pei. Research on Operation and Management Mode of the Optical Valley International Tennis Center. Science Innovation. Vol. 5, No. 6, 2017, pp. 360-364. doi: 10.11648/j.si.20170506.15

Received: August 9, 2017; Accepted: October 1, 2017; Published: October 27, 2017

\begin{abstract}
This study aims to study the applicability condition, the merits and demerits, the operation process and the mode points of the common operation mode of the large stadiums and gymnasium in China. Under the guidance of the operation orientation, from the reality of the optical valley international tennis center, to carry out a comprehensive analysis and demonstration, the full development of the use of venues resources, play the basic role of the market in the allocation of resources, so as to select the appropriate operation and management model to provide the necessary theoretical basis and clear operational thinking.
\end{abstract}

Keywords: Large Stadiums and Gymnasium, Operational Management, Mode, Optical Valley International Tennis Center

\section{光谷国际网球中心运营管理模式的研究}

刘培

职业网球学院, 武汉城市职业学院, 武汉, 中国

邮箱

378880308@qq.com

摘要：本研究拟对当下中国大型体育场馆常用运营模式的适用性条件、优劣特点、操作流程、模式要点等方面进行选 择性研究，在运营定位的指导下，从光谷国际网球中心的实际出发，进行全面分析论证，充分开发利用场馆资源，发 挥市场在配置资源中的基础作用，从而为其选择适宜的运营管理模式提供必要的理论依据和明确的操作思路。

关键词: 大型体育场馆, 运营管理, 模式, 光谷国际网球中心

\section{1. 引言}

大型体育场馆作为承办大型赛事的必要物质基础和 前提, 历来受到各级政府部门的重视, 各级政府曾先后 投入巨资修建了数量较多的大型体育场馆。在计划经济 时期, 国家对大型体育场馆实行统收、统支、统管, 经 费由国家统一下拨, 场馆功能比较单一, 使用率低[1]。 随着体制转轨, 体育由事业型向产业型转变, 而这一转
变的核心问题是所有权与经营权分离。经营权与所有权 如何分离, 则是选择何种运营模式的问题。众所周知, 体育场馆运营模式的选择对其经营状况的改善具有重要 的意义，而大型体育场馆如何根据其自身的特点选择科 学的、适宜的运营模式, 是目前亟待解决的一道难题[2]。 为了合理地搭建光谷国际网球中心的运营体系, 实现高 经济效益和社会效益的运营效果, 有效地加快武汉地区 网球运动的发展进程, 提升武汉市城市综合实力和影响 力, 选择适合光谷国际网球中心的运营模式迫在眉睫。 
本研究从光谷国际网球中心的实际出发, 进行全面 分析论证, 充分开发利用场馆资源, 发挥市场在配置资 源中的基础作用, 从而为其选择适宜的运营管理模式提 供必要的理论依据和明确的操作思路。

\section{2. 研究方法}

\section{1. 文献资料法}

查阅相关文献，系统地了解自 1984年来，大型体育 场馆由事业型管理向经营型管理的转变情况, 查阅国内 外有关大型体育场馆的运营管理、体育场馆与赛事运作、 体育场馆与大型文艺活动、体育社会学等方面的论文, 从多学科的视角来探讨湖北省大型体育场馆运营模式的 理论分析。

\section{2. 访谈法}

深入调查研究, 通过走访、座谈相关专业人士, 了 解有关体育行政管理部门、大型体育场馆运营管理企业、 体育场馆的管理人员等相关群体, 对大型体育场馆运营 管理的意见与建议, 获取深度的一线材料。

\section{3. 逻辑推理法}

以大型体育场馆与城市建设的相互关系为逻辑起点, 对收集的文献资料进行系统的分类整理, 归纳、推理出 相关结论, 完成从感性认识上到理性认识的过程, 在此 基础上撰写分析报告, 提出适合光谷国际网球中心的运 营管理模式。

\section{3. 结果与分析}

\section{1. 大型体育场馆主要运营管理模式及其优缺点分析}

目前, 中国大多数的大型体育场馆设施可选择的运 营管理模式主要有:

\subsection{1. 自主运营}

自主运营主要是大型体育场馆在体育行政部门的领 导下, 由政府全额或差额拨款, 体育场馆所属部门组织 一个机构或由专门的体育场馆管理人员负责其运营 [3]。 该方式运营压力较小, 有助于上级部门监督控制, 但场 馆利用率较低, 工作人员主观能动性一般不强。

\subsection{2. 合作运营}

指以大型体育场馆的土地、房屋或其他设施作为投 资，其他投资者以现金、设备、管理等作为投资，共同 运营大型体育场馆的运营模式。合作方式能够提高场馆 利用率并引进先进管理理念和经验, 但管理过程中权责 不够分明, 容易引起纠纷。

\subsection{3. 委托运营}

指大型体育场馆的业主将其拥有的大型体育场馆的 运营权委托给运营机构, 由该运营机构负责大型体育场
馆的运营。委托运营可以缓解财政负担, 提高场馆运营 效果, 但是场馆业主对运营方的过多干涉也可能会影响 场馆运营活动[3]。

\section{1. 4. 租赁运营}

指大型体育场馆的业主向承租人收取一定金额的租 金，而将场馆租赁给运营公司，运营公司自收自支。该 方式手续较简单, 能够减轻财政负担。

\section{2. 其他省市大型体育场馆运营管理模式的选择与借鉴}

中国大型场馆的运营管理存在多种模式，也面临许 多困惑, 怎么解决场馆运营中面临的困惑, 是我们长期 思考的问题 [4]。全面考察其他运营情况较好的大型体育 场馆所采用的运营管理模式, 可以给我们提供有益的借 鉴。

\subsection{1. 深圳湾体育中心运营管理模式分析}

深圳湾体育中心是一个大型综合性体育场馆。在设 计之初, 中日两家设计方就充分考虑了体育中心与周边 环境的融合。深圳湾畔所在地块是南山的一块宝地, 未 来的规划是高端金融商务区, 所以深圳湾体育中心也进 行了一体化紧凑设计。其以大型赛事为依托, 以全民健 身为重点, 目标是成为集体育比赛、运动训练、全民健 身、会展博览、商贸购物、文艺汇演、休闲娱乐、旅游 观光于一体的国际化综合性大型体育中心。其“一场两馆” 的一体化设计, 与商业设施、运动员接待中心复合, 更 有效、灵活的互相利用各种配套设施。

深圳湾体育中心的运营模式为委托经营, 由深圳南 山区政府将场馆委托给华润置地发展有限公司。双发达 成如下协议：1）政府设置公益活动指标；2）政府在法律 范围内争取给予华润置地最大程度的税收优惠;3）公益 性文体设施的土地税、房产税给予减免;4）维修、保养 费用由政府承担；）华润置地控股母公司进行连带责任 担保。

\subsection{2. 深圳龙岗体育中心（大运中心）运营管理模式分 析}

深圳龙岗体育中心所在的龙岗区, 以龙岗体育中心 为核心形成的“大运新城”, 带动了周边地区发展, 进一 步完善城市功能。大运中心的场馆建设使其周边地区的 基础设施建设水平实现大幅提升, 存量土地资源的发展 和深圳大运赛事带来的城市关注度, 使大运新城具备了 比其他新城更好的发展条件。其秉着“品牌价值高”与“远 离市中心”并存的发展理念, 周边配套主要设置五星级酒 店、商业步行街、极限运动城、国际自行车赛场、养生 会所、全民健身广场、运动员公寓等。

深圳龙岗体育中心的运营模式是以契约方式实现政 府所有、企业运营的产权分离体制, 明确场馆资产及周 边土地资源由市政府所有, 将资产委托龙岗区政府代管, 由区政府委托佳兆业集团控股有限公司运营。龙岗区政 府与佳兆业集团采用BOT的委托经营模式, 即政府部门 将大运场馆交给佳兆业以总运营商的身份进行运营管理, 
约定期限为 30 年。约定期限届满后, 场馆无偿交回给政 府部门。

\subsection{3. 广州国际体育演艺中心运营管理模式分析}

广州国际体育演艺中心位于广州萝岗区, 为广州亚 运会篮球比赛新建场馆。像美国体育馆诞生了 $\mathrm{NBA}$ 篮球 文化一样, 广州国际体育演艺中心想做的不仅是办几场 演出。其认为, 聚集人气, 传播文化, 才是一个场馆的 真正价值。为进一步让该场馆成为顶级娱乐目的地, 场
馆周边设置了许多商业娱乐区，包括购物中心、体育文 化广场、影院、音乐厅、五星级酒店等。

广州国际体育演艺中心采用委托经营模式, 由广州 开发区管委会批准、广州凯得控股有限公司出资设立全 资子公司--广州凯得文化娱乐有限公司投建场馆。经广州 凯得文化娱乐有限公司授权, 广州凯得体育文化发展有 限公司负责该场馆的运营、管理与推广。

\section{2. 4. 选择租赁运营模式的大型体育场馆分析}

表1 租赁运营模式场馆案例概要表。

\begin{tabular}{|c|c|c|c|c|c|c|}
\hline 体育场馆名称 & 规模 & 区位环境 & 租赁年限 & 出租方 & 承租方 & 运营方式 \\
\hline $\begin{array}{l}\text { 义乌梅湖体育中 } \\
\text { 心 }\end{array}$ & $\begin{array}{l}\text { 占地面积约 } 66.3 \\
\text { 公顷, 包括体育 } \\
\text { 场、体育馆和游 } \\
\text { 泳馆。 }\end{array}$ & $\begin{array}{l}\text { 位于义乌市中 } \\
\text { 心, 北临乌江, } \\
\text { 周边学校、住宅 } \\
\text { 较多。 }\end{array}$ & $\begin{array}{l}\text { 租赁期为 } 2002 \\
\text { 至2017年, 共 } \\
\text { 15年 }\end{array}$ & $\begin{array}{l}\text { 义乌国有资产 } \\
\text { 经营公司 }\end{array}$ & $\begin{array}{l}\text { 中国小 } \\
\text { 商品城 } \\
\text { 集团 }\end{array}$ & $\begin{array}{l}\text { 政府建设、企业运作。租赁期分为三个阶 } \\
\text { 段, 第一阶段为 } 3 \text { 年免租建设期, } 2005-2008 \\
\text { 年为试运营阶段, 租金 } 100 \text { 万元/年, 第三阶 } \\
\text { 段每年上缴租金 } 450 \text { 万元。从 } 2002 \text { 年运营至 } \\
2006 \text { 年, 已举办 } 66 \text { 项大型体育文化活动, 不 } \\
\text { 少赛事具有重大影响力。 }\end{array}$ \\
\hline $\begin{array}{l}\text { 北京国家网球中 } \\
\text { 心 }\end{array}$ & $\begin{array}{l}\text { 占地面积 } 16.68 \\
\text { 公顷, 共 } 18 \text { 片网 } \\
\text { 球场地, 主场馆 } \\
\text { 有可开合屋顶 }\end{array}$ & $\begin{array}{l}\text { 位于朝阳区奥林 } \\
\text { 匹克森林公园 } \\
\text { 内, 北邻北五 } \\
\text { 环, 附近有地铁 } \\
\text { 站, 交通便利。 }\end{array}$ & 短期赛时租赁 & $\begin{array}{l}\text { 世奥森林公园 } \\
\text { 公司 }\end{array}$ & $\begin{array}{l}\text { 北京中 } \\
\text { 网公司 }\end{array}$ & $\begin{array}{l}\text { 中网公司只在中网公开赛时租赁场地, 不负 } \\
\text { 责安保、保洁、设备操作等工作, 费用每年 } \\
\text { 约 } 1100 \text { 万。通过短期租赁节约成本并将重点 } \\
\text { 放在赛事上, 中网公开赛已成为北京的品牌 } \\
\text { 赛事之一。 }\end{array}$ \\
\hline $\begin{array}{l}\text { 上海旗忠网球中 } \\
\text { 心 }\end{array}$ & $\begin{array}{l}\text { 占地面积 } 5.08 \text { 公 } \\
\text { 顷, 共 } 25 \text { 片网球 } \\
\text { 场, 主场馆有可 } \\
\text { 开合屋顶。 }\end{array}$ & $\begin{array}{l}\text { 上海西南闵行区 } \\
\text { 马桥镇, 位置较 } \\
\text { 偏远。 }\end{array}$ & 短期赛时租赁 & $\begin{array}{l}\text { 闵行城市建设 } \\
\text { 投资开发公司 }\end{array}$ & $\begin{array}{l}\text { 上海久 } \\
\text { 事公司 }\end{array}$ & $\begin{array}{l}\text { 久事公司只在上海劳力士大师赛时租赁场 } \\
\text { 地, 不负责安保、保洁、设备操作等工, 费 } \\
\text { 用为每年 } 1000 \text { 万左右。 }\end{array}$ \\
\hline
\end{tabular}

通过对上述选择租赁运营模式的大型体育场馆的分 析, 我们得出: 1) 在场馆能够承办多种体育项目的情况 下, 通过租赁模式将场馆的所有权与经营权适当分离, 以体育赛事为主, 将体育场馆进行市场化操作, 利用体 育赛事与城市发展的良性互动, 可以实现业主、运营方 的共赢；2）在场馆功能单一的情况下，运营公司以短期 赛时租赁为主, 将主要工作重心放在打造赛事品牌上, 压缩成本节约人力, 从而实现公司的盈利；3）租赁运营 模式不涉及场馆产权的转让, 房产税和土地使用税仍由
业主缴纳，因此运营方可以节省支出; 运营方能够在市 场经济条件下, 较为自由的开展经营活动, 不受业主的 过多干涉，因此经营积极主动性较高。

\subsection{5. 选择委托运营模式的大型体育场馆分析}

前文详细介绍的深圳湾体育中心以及深圳龙岗体育 中心都为典型的委托运营模式，这里不再赘述。下文列 举几个其他城市采用委托运营模式的大型体育场馆。

表2 委托运营模式场馆案例概要表。

\begin{tabular}{|c|c|c|c|c|c|c|c|}
\hline $\begin{array}{l}\text { 体育场 } \\
\text { 馆名称 }\end{array}$ & 规 模 & 区位环境 & $\begin{array}{l}\text { 委托 } \\
\text { 经营 } \\
\text { 范围 }\end{array}$ & $\begin{array}{l}\text { 委托运 } \\
\text { 营年限 }\end{array}$ & 业主方 & 管理方 & 合同要点概述 \\
\hline $\begin{array}{l}\text { 安徽合 } \\
\text { 肥奥体 } \\
\text { 中心 }\end{array}$ & $\begin{array}{l}\text { 占地面积 } 521 \text { 亩, 建筑面 } \\
\text { 积 } 15.3 \text { 万平方米, 总投 } \\
\text { 资约 } 15 \text { 亿元。包括一座 } \\
\text { 主体育场、一座综合体 } \\
\text { 育馆、一座游泳跳水 } \\
\text { 馆、一个三星级的体育 } \\
\text { 宾馆及附属用房等设施 }\end{array}$ & $\begin{array}{l}\text { 位于合肥市政务文 } \\
\text { 化新区南部, 北临 } \\
\text { 习友路, 南临环区 } \\
\text { 南路, 西临奥体西 } \\
\text { 路, 东临潜山路, } \\
\text { 交通便利, 属于未 } \\
\text { 来政务文化集中区 }\end{array}$ & $\begin{array}{l}\text { 建设用地红 } \\
\text { 线范围内建 } \\
\text { 筑、场地、 } \\
\text { 设施设备、 } \\
\text { 物品等物业 }\end{array}$ & $\begin{array}{l}\text { 2010年 } \\
\text { 始 }\end{array}$ & $\begin{array}{l}\text { 合肥政 } \\
\text { 务文化 } \\
\text { 新区开 } \\
\text { 发投资 } \\
\text { 有限公 } \\
\text { 司 }\end{array}$ & $\begin{array}{l}\text { 中体产 } \\
\text { 业集团 } \\
\text { 股份有 } \\
\text { 限公司 }\end{array}$ & 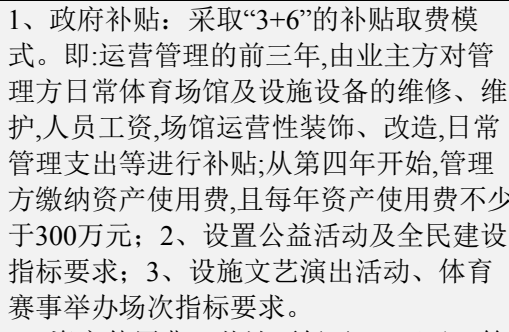 \\
\hline $\begin{array}{l}\text { 马鞍山 } \\
\text { 市体育 } \\
\text { 会展中 } \\
\text { 心 }\end{array}$ & $\begin{array}{l}\text { 项目总占地面积约 } 750 \\
\text { 亩, 总建筑面积约 } 17.1 \\
\text { 万平方米, 包括“一场四 } \\
\text { 馆”（体育场、体育馆、 } \\
\text { 游泳馆、网球馆、会展 } \\
\text { 中心） }\end{array}$ & $\begin{array}{l}\text { 位于安工大东校区 } \\
\text { 以北, 霍里山大道 } \\
\text { 以东, 地处主城区 } \\
\text { 与秀山新区交界 } \\
\text { 处, 交通便利, 为 } \\
\text { 地标性建筑群 }\end{array}$ & $\begin{array}{l}\text { 综合体育 } \\
\text { 馆、会展中 } \\
\text { 心、主体育 } \\
\text { 场、游泳 } \\
\text { 馆、网球馆 } \\
\text { 及其外环境 } \\
\text { 范围内的资 } \\
\text { 产 }\end{array}$ & $\begin{array}{l}\text { 13年 } \\
\text { 2013年 } \\
\text { 始 }\end{array}$ & $\begin{array}{l}\text { 马鞍山 } \\
\text { 市城市 } \\
\text { 发展投 } \\
\text { 资集团 } \\
\text { 有限责 } \\
\text { 任公司 }\end{array}$ & $\begin{array}{l}\text { 赛维爱 } \\
\text { 玛 (北 } \\
\text { 京) 体 } \\
\text { 育文化 } \\
\text { 发展有 } \\
\text { 限公司 }\end{array}$ & $\begin{array}{l}\text { 1、资产使用费: 共计不低于 } 500 \text { 万元, 管 } \\
\text { 理方分年支付; } 2 \text { 、履约保证金共计 } 300 \text { 万 } \\
\text { 元; 3、业主方给予体育会展中心的大型 } \\
\text { 建筑和重要设备设施的大修理费用全额财 } \\
\text { 政资金补贴。4、设置公益活动、全民健 } \\
\text { 身及举办体育赛事、文化演出活动、会议 } \\
\text { 节庆展览场地指标要求; 5、设置优先保 } \\
\text { 障政府性活动指标要求。 }\end{array}$ \\
\hline
\end{tabular}


通过对上述采用委托运营模式的大型体育场馆的分 析, 我们发现：1）委托运营模式成为当前大型体育场馆 的主要运营模式选择, 并且从体育产业发展趋势来看, 大型体育场馆受托管理方由专业体育企业承担的趋势越 来越明显, 且专业体育企业能够很好地发挥其专业化管 理优势；2）委托运营模式下，业主方和管理方的权利和 义务在委托合同中得到明确, 委托年限由业主运营理念、 当地体育产业发展趋势及场馆规模属性等因素决定; 为 了使场馆前期实现良性运作，业主方一般会给予适当的 经费补贴, 同时创造各种条件便于管理方的运营管理; 且各类运营指标要求的设置在保障体育场馆公益性的同 时, 也是作为对管理方运营效果的考察条件；3）在委托 运营模式下, 管理方能够充分发挥自己的运营能动性, 能够实现经济效益最大化的目标, 以减轻政府财政负担。

\section{3. 湖北省主要大型体育场馆运营管理模式分析}

\section{3. 1. 湖北省武汉市民之家的运营管理模式}

湖北省武汉市的武汉市民之家采用是典型的自主运 营模式。市民之家是由市政府投资，武汉地产集团建设 并运营管理。武汉地产集团从房屋出租、经营或非经营 区域出租、停车场、物业管理收费等几方面对市民之家 进行经营管理, 市政府进行差额拨款, 从而达到提供社 会服务、体现社会效益的目标[5]。

\section{3. 2. 湖北省武汉体育中心的运营管理模式}

湖北省武汉体育中心是由武汉经济开发区管委会投 资建设，委托给开发区国资办独资公司武汉体育中心发 展有限公司全权经营。武汉体育中心以提供专业、高等 体育赛事和商业演出为主, 其次提供全民健身等公共服 务[6]。政府每年按 2000 万一 3000 万进行补贴。

\section{4. 光谷国际网球中心适用性运营管理模式的选择建议}

\section{4. 1. 光谷国际网球中心项目背景分析}

武汉光谷国际网球中心（以下简称网球中心）于 2014年至2018年承办“世界女子职业网球赛WTA超五巡回 赛” (以下简称“超五巡回赛（武汉站）”），该赛事由国 际女子职业网联（WTA）主办, 奖金和积分仅次于WTA 皇冠赛, 赛事级别较高。

为了更好地保障“超五巡回赛 (武汉站)”的顺利举 办, 创造优质的群众观赛环境; 敏锐地捕捉网球运动市 场变化特点, 释放网球消费需求; 合理地搭建网球中心 运营体系, 实现高经济效益和社会效益的运营效果; 有 效地加快武汉地区网球运动的发展进程, 提升武汉市城 市综合实力和影响力; 选择适合网球中心的运营模式迫 在眉睫。

\section{4. 2. 光谷国际网球中心运营管理规划的总体定位}

武汉市是中国网球发展的重要城市, 也是中国网球 经济发展最成熟的地区, 随着“WTA超五巡回赛”这一顶 级赛事的落户, 武汉将成为世界瞩目的焦点。而对于 “WTA超五巡回赛”的比赛场馆——武汉光谷国际网球中
心（以下简称“网球中心”) 的建设和运营, 人们也提出 了更高的要求。为了能够有效地化解场馆建设与赛后运 营之间的矛盾, 使体育场馆设施创造更大的社会效益和 经济效益, 本研究通过对网球中心运营特点的分析总结, 提出了适宜的运营初步方案。

鉴于网球中心独特的区位环境, 武汉市将网球中心 总体定位为国际网球主题公园, 通过对场馆及其配套设 施的综合开发, 形成集体育赛事欣赏、网球文化推广、 体育运动培训、休闲娱乐旅游于一体的、多元化消费服 务场所, 为武汉市民及世界网球运动爱好者带来优质的 网球赛事观赏效果及丰富的体育项目消费体验; 为群众 提供优质的体育公共产品, 打造开放、现代、时尚、潮 流的体育运动休闲公园; 通过对场馆的市场化运营, 充 分发挥品牌赛事的放大效应, 促进体育产业及关联产业 的可持续发展, 优化产业结构, 带动区域经济发展 [7], 最终成为武汉市新的城市名片。

\subsection{3. 光谷国际网球中心运营管理规划的功能板块定位}

根据网球中心总体定位, 结合中心运营目标及场馆 设施特点, 将网球中运营划分为四大功能板块:

（1）体育赛事板块：以“WTA超五巡回赛”为主, 引入各级别网球赛事, 形成层次化、规模化网球赛事板 块, 同时引进武汉市民喜爱的羽毛球赛事、篮球赛事等, 丰富网球中心体育赛事体系; (2) 文化演艺板块: 以年 轻化文艺系列演出形式为主, 如草莓音乐节、迷笛音乐 节等, 集聚人气; 发展具有较高上座率的一、二线明星 演唱会, 推广本地特色演出形式, 以丰富文化演艺活动; （3）体育培训板块: 以青少年网球运动培训为主, 联合 奥体中心体育项目设施, 开发与网球相呼应的体育运动 培训内容: 高尔夫运动; (4) 主题休闲娱乐板块: 以 “主题区”为板块构成元素, 包含主题餐饮区、主题酒吧 区、主题网球体验区、主题休闲区、主题运动区、主题 网球博物馆区、企业俱乐部等。

\section{4. 4. 光谷国际网球中心运营管理模式的选择原则}

光谷国际网球中心的运营目标, 是在“专业化管理” 的指导原则下, 有效整合优质资源, 提高网球中心专业 化管理水平, 在保障WTA超五巡回赛（武汉站）的顺利 举办的同时, 满足网球中心社会、经济效益最大化的经 营目标, 从而进一步扩大网球中心的影响力, 有提升武 汉市的城市形象和城市竞争。

参照光谷国际网球中心的建造目的及其定位, 本研 究为其选择运营管理模式提供了几个基本原则: 1) 优化 网球中心资源配置, 提升网球中心运营水平, 降低运营 风险, 促进“WTA超五巡回赛（武汉站）”的可持续发展; 2) 主导网球产业价值链建设, 合理开发与利用其它体育 项目资源, 实现网球中心多元化经营目标 [8]; 3) 确保网 球中心专业化管理质量, 提升区域内场馆服务水平, 加 大网球中心社会效益影响力; 4) 有效提高单位成本收益, 实现“降本增效”的总目标, 最终减轻政府财政负担 [9]。 


\section{4. 5. 光谷国际网球中心运营管理模式的选择建议}

目前, 国内大型体育场馆的运营主要有租赁运营、 委托运营等多种模式, 模式的选择主要取决于场馆的核 心定位。场馆的运营管理, 既要体现公益性作用, 又要 创造经济效益; 既要提高市场竞争力, 促进体育产业持 续发展, 又要展现城市发展美好形象 [10]。

租赁运营模式下，运营方将重心放在打造赛事品牌 上, 能够较自由的开展经营活动, 最大限度创造经济效 益。上海旗忠网球中心及北京国家网球中心采用都是租 赁运营的模式。委托运营模式下, 运营方能够保障场馆 公益性, 同时还能够结合体育产业发展, 对场馆进行多 元化开发。委托经营模式是当前大型场馆的主要运营模 式, 武汉体育中心及武汉琴台大剧院采用的是委托运营 管理模式。

根据其他省市大型体育场馆与湖北省主要大型场馆 运营模式的分析, 结合光谷国际网球中心运营管理规划 的总体定位, 综合来看, 委托运营模式更符合场馆运营 管理需求。委托运营模式能够充分发挥场馆的公益性, 更大程度上获得政府政策支持, 更全面对场馆及配套设 施进行开发, 更好地促进体育产业及其关联产业发展, 更大限度实现经济效益, 更好地展现城市的知名度与美 誉度。

\section{5. 研究结论}

根据光谷国际网球中心运营定位及运营目标, 结合 网球中心固有的社会属性特点, 通过本文研究分析, “委 托运营模式”较为符合网球中心的运营定位和运营需要, 能够很好地实现网球中心的建设目标。委托运营模式下, 通过“专业化管理”手段，实现优质资源的有效整合，从 而能够提高网球中心专业化管理水平，在保障“WTA超五 巡回赛”的顺利举办的同时, 最大程度地满足网球中心社 会、经济效益最大化的经营目标, 从而进一步扩大网球 中心的影响力, 有提升武汉市的城市形象和城市竞争。

\section{致谢}

本文为湖北省体育社会科学研究课题一般项目《湖 北省大型体育场馆运营管理模式的研究》 (2015B013)的 阶段性成果之一。

\section{参考文献}

[1] 陈元欣, 刘倩. 我国大型体育场馆运营管理现状与发展研 究 $[J]$. 体育成人教育学刊. 2015(6):23-31。

[2] 陈元欣. 大型体育场馆多元化经营研究 [J]. 体育成人教育 学刊, 2013(4):1—6。

[3] 雷厉, 肖淑红, 付群, 陈莉.我国大型体育场馆运营管理: 模式选择与路径安排 $[\mathrm{J}]$. 北京体育大学学 报. 2013(10):10-15。

[4] 徐文强, 陈元欣, 张洪武, 王健. 中国公共体育场馆经营 现状及管理体制改革研究 [J]. 成都体育学院学报, 2007年 03 期: $1-6$.

[5] 湖北省公共体育场馆协作会. 湖北省公共体育场馆贯彻落 实八部委文件工作推进会资料汇编[Z]．2013。

[6] 何开文. 湖北大型体育场馆运营管理模式探索 $[\mathrm{N}]$. 中国体 育报, 2013（02）。

[7] 原玉杰, 靳英华. 体育场馆布局的影响因素分析[J]. 北京体 育大学学报, 2007(11)。

[8] 肖淑红, 付群. 我国大型体育场馆融资模式分析及发展趋 势研究[J]. 西安体育学院学报, 2012(9):513-516。

[9] 陈元欣. 大型体育场馆多元化经营研究 [J]. 体育成人教育 学刊, 2013(4):1一6。

[10] 张仁寿. 大型体育场馆建设和运营研究 [J]. 体育文化导刊, 2009(11):88-92。

[11] 伊也意, 孙巧. 体育产业在我国国民经济中的地位和作用 [J]. 青年与社会. 2014(7)：141-143。

[12] 徐卫华, 王德平, 张京. 中美体育场馆冠名权出让比较研 究[J]. 体育文化导刊, 2011，01：89-92。

[13] 萨瓦斯（美）. 民营化与公私部门的伙伴关系[M]. 北京: 中国人民大学出版社, 2002, 6。

[14] 刘波, 邹玉玲. “公共物品理论” 视角下中国公共体育场 馆民营化改革的思考 [J]. 首都体育学院学报, 2008, 07:46-48。 